\title{
Pseudomonas Infections in Surgery Practice Needs for Innovative Antimicrobial Procedures?
}

\author{
Germano Orrù ${ }^{*}$, Alessandra Scano ${ }^{1}$, Vincenzo Piras ${ }^{2}$, Gloria Denotti ${ }^{2}$, Manuele Liciardi $^{3}$, Giuseppe Speziale $^{4}$, \\ Claudio Napoleone ${ }^{5}$ and Andrea Mascolo ${ }^{6 *}$ \\ ${ }^{1}$ Molecular Biology Service-AOU-Cagliari, Italy \\ ${ }^{2}$ Institute of Dentistry, University of Cagliari, Italy \\ ${ }^{3}$ Zooprophilatic. Institute of Sardinia Cagliari, Italy \\ ${ }^{4}$ Cardio Surgery Department - Anthea Hospital - Bari, Italy \\ ${ }^{5}$ Dental Operative Unit - Villa Lucia Hospital- Conversano(BA)- Italy \\ ${ }^{6}$ LUDES Foundation H.E.I. - Malta
}

Submission: April 13, 2017; Published: April 17, 2017

*Corresponding author: Germano Orrù, Department of Molecular Biology Science, AOU-Cagliari, Italy, Email: orru@unica.it;

Andrea Mascolo, Associate Professor, LUDES Foundation, HEI Malta, Europe, Tel: 393394 966412; Email: andrea.mascolo@ludes.edu.mt

\section{Mini Review}

\section{From environment to patient}

Pseudomonas genus is known and studied from many years and it's currently widely to the attention in microbiological and in medical clinical area for severe infections occur in patients who are already illness or who have a weak immune system, such as long term hospitalized subject. This bacteria group, normally is isolated in the environment, such as in soil, water, plants and in nosocomial area as well as in veterinary field such as intensive no controlled farming [1]. Pseudomonas spp. represents a Gram negative opportunistic pathogens bacteria group with a great, outstanding adaptability in the different environmental conditions. In fact, recentstudies by using the comparative genomics on different strains of $P$. aeruginosa isolated in human and veterinary field have identified some key genes involved in the shift environment-status vs. pathogenstatus of these bacteria.

In particular, these studies have been reported a significant variations as single nucleotide polymorphisms (SNPs) and minor insertion/ deletion variations in genes associated with biofilm formation and twitching motility. A structured biofilm appears crucial in $P$. aeruginosa pathogenicity because the sessile condition carries some pretty significant payoffs in comparison with the planktonic counterpart [2]. The major benefits associated with the biofilm condition for P. Aeruginosa are related at:

(i) the bacterial cells are encased in an extracellular polysaccharide matrix containing alginate and this is extremely impenetrable to antibiotics. In fact to eradicate the Pseudomonas biofilm by antimicrobial was found to be 10-100times higher as compared to that used to eradicate the same cells in the planktonic status.

(ii) Furthermore, the host immune system recognition such as phagocytosis or the antibody-bacteria surface interaction in Pseudomonas biofilms are strongly impaired.

(iii) the biofilm formation requires, in these bacteria, a complex shift in the transcriptome profile with an increase of the virulence/pathogenicity outline, i.e. the production of toxins, proteases, enzymes able to injure the host's tissues [3]. For this reason, the presence of a consistent Pseudomonas biofilm contamination in the surgical areas could be a great risk for the patient, and health care workers must implement all of hygiene procedures.

\section{Pseudomonas infections in the surgical practice}

Many studies have reported the surgical Intensive Care Unit (ICU) as the focal point on the patient 'risk for different microbial infections related at nosocomial modality transmission [4]. The high incidence of infections in ICUs patients is due at different concomitant conditions, use a broad-spectrum antibiotics, devices placed with interventional techniques, mechanical ventilation and cross infection with multi-drug resistant Pseudomonas strains, as well as other microorganisms [5]. In the hospital structures the "Pseudomonas contamination hot points" have been identified by different studies and water pipelines such as contaminated sink trap, dental unit water lines and air humidifiers represent the first studied topics $[4,6,7]$. Another field represent the infections that occur during the surgery procedures (Figure 1) [8-17]. These data suggested that after the intensive care units, ocular and cardiovascular surgery 
represents hospital wards with high risk for infections often related at Pseudomonas aeruginosa multidrug resistant strains

(MDR) (Figure 1) [18].

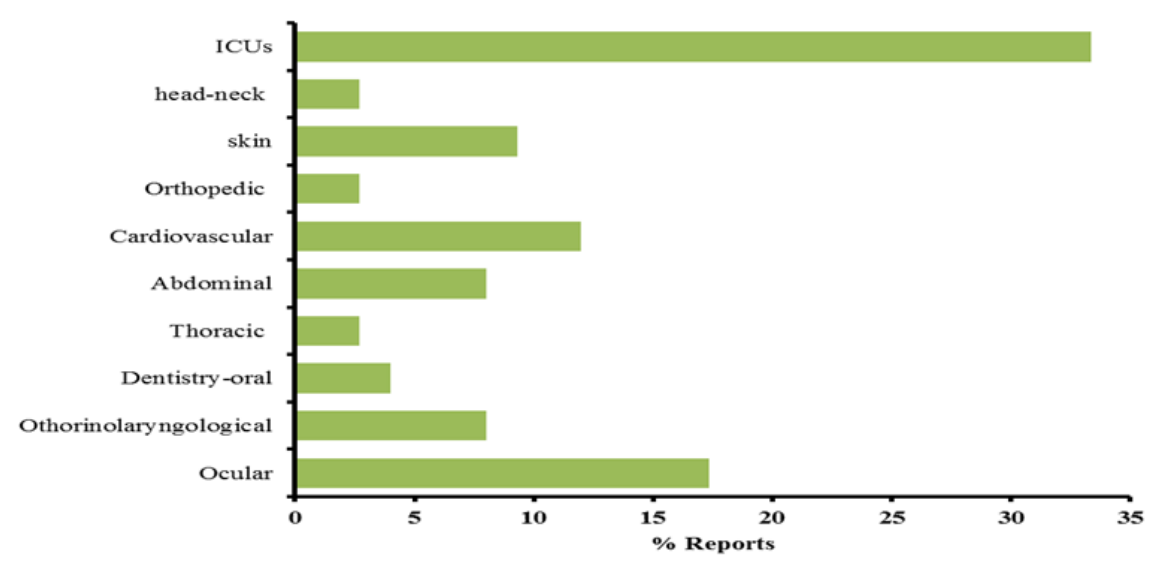

Figure 1: Surgical-site and complications due to Pseudomonas infections reported on PubMed data.

\section{The antimicrobial resistance in Pseudomonas spp}

Within the genus Pseudomonas, P. aeruginosa represent the first specie related at nosocomial/surgical infections and the third most common cause of health-care associated infections. Furthermore a considerable number of virulence factors, included antimicrobial resistance mechanisms have been discovered in this bacterium. For this reason, P. aeruginosa is considered a "superbug". This microorganism is able to escape the antimicrobial therapies or prophylactic antisepsis procedures through genetic and epigenetic adaptive strategies [19]. A point of concern is the presence in nosocomial area of multidrug resistant strains (MDR), i.e.which is resistant to more than one antimicrobial agent in three or more antimicrobial categories, or extensively drug resistant (XDR) strains, which is resistant to more than one antimicrobial agent in all the antimicrobial categories, except in two or less.

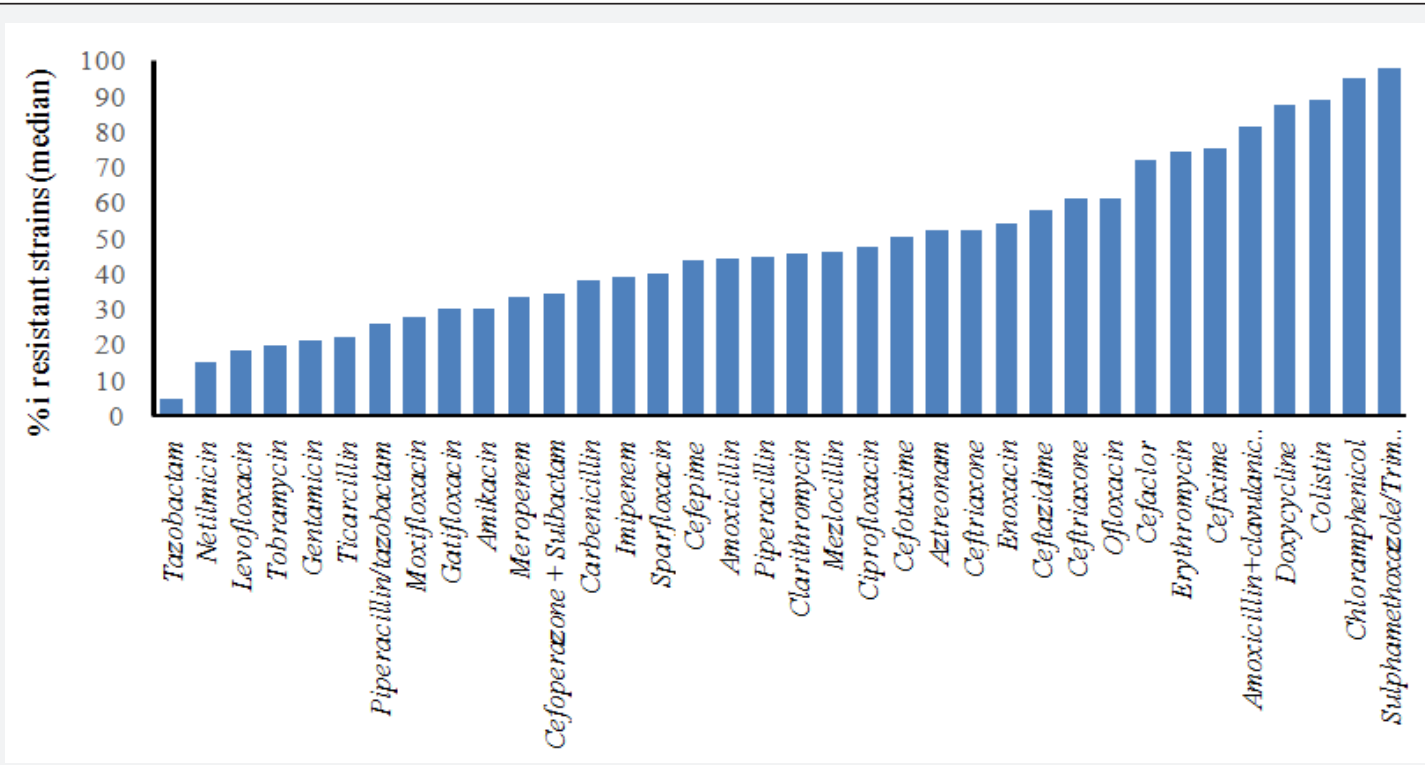

Figure 2: Drug resistance rate \% of Pseudomonas spp. clinical isolates. 2015-2017 worldwide report.

In addition, Pan-DR (PDR) phenotype is defined as a bacterium which is resistant to all antimicrobial agents in all antimicrobial categories [20]. Sader et al. [21] have published the rate of multidrug resistant strains of $P$. aeruginosa referred to USA from 2012 to 2016 . MDR-XDR phenotypes were observed among $15.4 \%$ and $9.4 \%$ respectively. Pseudomonas spp, exhibit a serious therapeutic challenge for treatment in the nosocomial infections, and selection of the correct antibiotic therapy is essential to optimizing the clinical outcome. Unfortunately this selection could result complex for the ability of this genus, especially P. aeruginosa, to develop resistance to multiple classes of antibacterial agents, even during the course of treating an infection [22-30], (Figure 2). 
Another similar problem is represented with liquid disinfectants for treated Pseudomonas biofilm in the nosocomial area. Different studies showed that P. aeruginosa is about 200300 -fold more resistant when present on contaminated medical surfaces than in planktonic status. Considering different germicidal agents used in commercial liquid disinfectants such as: glutaraldehyde, formaldehyde, peracetic acid, hydrogen peroxide, sodium hypochlorite, phenol, and cupric ascorbate, these microorganisms have demonstrated an incredible ability to avoid their antibacterial activity. For example the currently use of hydrogen peroxide can cause mutations in the muc operon with a consequent overproduction of alginate in the biofilm matrix, this cause waterproof to many disinfectants [31].

\section{Strategies to prevent Pseudomonas infections in the surgical field}

The last reports on Pseudomonas spp. infections in nosocomial/surgical field reported these bacteria as "perfect war machine "and for this reason as proof of concept, many researchers have been focusing on new therapeutic strategies for novel antimicrobials and showing interest in new bioactive molecules by chemical synthesis or extracted from plants [32]. Actually, three different areas are involved in the study for new antimicrobials:

(i) synthesis of new chemical compounds especially gold/ silver complex [33],

(ii) new antibiotics,

(iii) biological active extracts i.e. essential oils [32]. Different reports as well as the Center for Disease Control (CDC), for nosocomial infection surveillance, has classified sites into 13 types, with 50 infection site, and most of these are related at surgical or post-surgical procedures [34,35]. These report recommended a precise and specific procedure inside the surgical areas for minimize these infections, in particular:

i. Measurement of Pseudomonas infection rates: It is important to know the types of Pseudomonas specie and the genotypes profile involved and their correct location inside the patient's body and in the surgical area. In fact, Pseudomonas spp. is an extremely heterogeneous bacterium which makes them different from one another. It is possible that in a nosocomial area the rates of infection are similar, while the genetic variations of the different strains significantly differ.

ii. Infection and surveillance control programs: The primary focus of an infection control program in the hospital is to prevent and control hospital-acquired pathogens outbreak, in this context operative guidelines and training of healthcare professionals must be the core for an efficient control.This program must contain operative protocols for the sterilization and disinfection of invasive devices and medical instruments used for surgeries, i.e. autoclave management and control systems, storage use and dilution of liquid disinfectants etc. In addition, a good network with the microbiological laboratory is required for discover, in short time, the presence of superbugs in the surgical ward.

\section{Conclusion}

In the globalization era, the role of Pseudomonas genus, as nosocomial pathogen, is strictly related at the fast spread between different countries of strains with high pathogenicity profile, such as MDR or XDR clinical isolates, these "superbacteria" could be transmitted by animals or healthy subjects and make it extremely difficult to devise a proper plan and its implementation for a worldwide control, in addition there is a lack of epidemiological data for Pseudomonas infections in developing countries, regarding causes, pathogenicity profile and antimicrobial susceptibility. For this reason, to minimize such infections in surgical areas, adherence of strict aseptic protocols, an effective environmental control for bacterial contamination and new strategies of post surgical management of wounds is greatly required.

\section{References}

1. Kallio KB (1932) Uber Volvulus Coli Transversii. Act Chir Scand 70: 3958.

2. Ballantyne GH, Brandner MD, Beart RW, Ilstrup DM (1985) Volvulus of the Colon Incidence and Mortality. Ann Surg 202(1): 83-92.

3. Waluza JJ, Aronson DC, Nyirenda D, Zoetmulder FA, Borgstein ES (2015) Transverse colon volvulus in children: A case series and a review of the literature. J Pediatr Surg 50(10): 1641-1643.

4. Rahbour G, Ayantunde A, Ullah MR, Arshad S, Kerwat R (2010) Transverse colon volvulus in a 15 year old boy and the review of the literature. World J Emerg Surg 5: 19.

5. Newton NA, Reines HD (1977) Transverse Colon Volvulus: Case Reports and Review. Am J Roentgenol 128(1): 69-72.

6. Mark J Sage, Jenan Younis, Katie Schwab, Keith A Galbraith (2012) Colopexy as a treatment option for the management of acute transverse colon volvulus: a case report. Journal of Medical Case Reports 6(1): 151.

7. Walczak DA, Czerwińska M, Fałek W, Trzeciak PW (2013) Volvulus of transverse colon as a rare cause of obstruction - a case report and literature review. Polski Przegląd Chirurgiczny 85(10): 605-607. 
This work is licensed under Creative Commons Attribution 4.0 Licens DOI: 10.19080/OAJS.2017.03.555619

\section{Your next submission with Juniper Publishers will reach you the below assets}

- Quality Editorial service

- Swift Peer Review

- Reprints availability

- E-prints Service

- Manuscript Podcast for convenient understanding

- Global attainment for your research

- Manuscript accessibility in different formats ( Pdf, E-pub, Full Text, Audio)

- Unceasing customer service

Track the below URL for one-step submission https://juniperpublishers.com/online-submission.php 